\title{
Study on Aerobic Bacterial Etiology of Chronic Osteomyelitis after Compound Fractures in a Tertiary Care Centre in South India
}

\author{
Authors \\ Dr Chinnu Sajeev ${ }^{1}$, Dr Saritha. ${ }^{2}$, Dr Shobha Kurian ${ }^{3}$ \\ ${ }^{1}$ Department of Microbiology, Government Medical College, Trivandrum \\ ${ }^{2}$ Associate Professor, Department of Microbiology, Government Medical College, Trivandrum \\ ${ }^{3}$ Professor, Department of Microbiology, Government Medical College, Kottayam \\ Corresponding Author \\ Dr Chinnu Sajeev
}

Souharda-83, Manicheril, Trivandrum

Email: chinnusajeev@yahoo.com, Mobile-9400616614

\begin{abstract}
Introduction: Post traumatic osteomyelitis is one of the few infectious diseases which has become prevalent due to high speed motor vehicle accidents and orthopedic surgery. The deep infection rate in setting of open fracture ranges from 2 to $50 \%$ as trauma exposes bone by breaching host defences and provides ideal environment for colonisation.

After diagnosing chronic osteomyelitis, treatment is aimed at eradicating infection and to prevent recurrence. However osteomyelitis is often unresponsive to modern therapy and although mortality has been eliminated, it still often results in morbidity and disability. Management of chronic osteomyelitis with proper antibiotic therapy based on culture report is necessary for full cure. Though earlier studies gram positive organisms were the main pathogens, now other gram negative bacilli like pseudomonas and klebsiella are also frequently isolated from hospitalized patients and are commonly associated with recurrence.
\end{abstract}

Aim

1. Our study aims to find out the incidence of osteomyelitis in compound fracture patients, in a tertiary care centre.

2. To find the etiology and its antibiotic sensitivity so that effective pathogen directed treatment can be given.

3. To find incidence of ESBL AND MBL organisms causing infections.

Materials and Methods: A descriptive study of specimens collected from patients admitted under orthopaedic department wards in Govt medical college Trivandum from july 2013 to july 2014.

Patients aged more than 20 years age with clinical and radiological features of chronic osteomyelitis.About 150 patients who were admitted in the orthopedic wards during time period of one year was taken into consideration.

Data was obtained in structured proforma and correlated with their clinical history and sample collection was done from each patient.

Results: Out of 150 patients studied with chronic osteomyelitis, open fractures were most associated with chronic osteomyelitis. More gram negative especially ESBL resistant organisms were isolated from cases. Moreover the number of MRSA cases were reduced compared to the previous study done in the same ward by Dr. Shanimole et al ${ }^{l}$. 
Conclusion: Increased isolation of multidrug resistant organisms among cases imply the uncontrolled use of high level antibiotics in the initial stage itself. Moreover the implementation of proper MRSA isolation precautions lead to a dramatic decrease in MRSA cases in the ward compared to previous study. Etiology directed treatment yielded better cure rate during Follow up.

Keywords: ESBL- Extended spectrum beta lactamase MBL-Metallo beta lactamase, MRSA-Methicillin resistant staphylococcus aureus.

\section{Introduction}

Infection of bones and joints are becoming common nowadays as there is an increase in number of road traffic accidents with resultant fractures and associated infections.So prolonged etiology directed treatment with antibiotics and surgical management is necessary for complete recovery and to prevent further relapses.

Chronic osteomyelitis commonly involves long bones, especially tibia and femur ${ }^{2}$.Microorganisms from skin wounds and other infectious regions reach metaphysis of bone through blood.

The most important risk factor of osteomyelitis are trauma (primarily open fractures and severe soft tissue injury), vascular insufficiency, diabetes, elderly, children, obesity, surgical wound infection, mismanagement of acute osteomyelitis and haemoglobinopathies like sickle cell disease. Diagnosis of osteomyelitis depends on clinical features, X- ray findings (bone lucency mixed with patchy sclerosis and adjacent periosteal new bone formation, MRI and confirmation of the diagnosis is by blood culture and /or culture of bone aspirate or biopsy ${ }^{3}$.

Several studies report that the definitive diagnosis of chronic osteomyelitis is by isolating the bacteria from the intra operative biopsy specimen of the involved bone. Contaminated open fractures can lead to development of osteomyelitis of fractured bone typically at fracture site in 3 to $25 \%$ of cases ${ }^{4}$. The factors favouring infection by these organisms are production of surface factors, secreted proteins, biofilm formation, capsule, secreted enzymes and hemolysins, ${ }^{, 5}$ High prevalence rate of anaerobic bone infection was found especially in chronic cases. Hence anaerobic culture is also recommended for all cases with osteomyelitis ${ }^{6}$
Early bacteriological investigations to determine etiology and their antibiotic sensitivity pattern are highly desirable so that unnecessary use of broad spectrum/ second/ third line antimicrobials can be avoided.In this context the present study was undertaken to find the aerobic bacterial etiology on chronic osteomyelitis in patients who had sustained compound fractures and the effect of proper culture directed therapy.

\section{Materials and Methods}

\section{Objectives of Study}

1. To find the incidence and to identify the aerobic pathogenic bacteria causing chronic osteomyelitis in patients with compound fractures.

2. To evaluate antibiotic sensitivity pattern of these pathogenic bacteria.

3. To identify MBL and ESBL organisms among the isolates

Study Design: Cross Sectional Study

\section{Study Setting:}

1. Department of Microbiology, Governement Medical College,Trivandrum

2. Department of Orthopeadics, Governement Medical College, Trivandrum

Study Period: One year (July 2013-June2014)

\section{Study Population}

\section{Inclusion Criteria}

- Patients more than 20 years of age with clinical and radiological features of chronic osteomyelitis.

\section{Exclusion Criteria.}

- Patients aged less than 20 years.

- Patients with vertebral osteomyelitis.

- Patients suffering from immunosuppressive disease and degenerative joint disease.

Sample Size- was fixed as 150 
The patient information like personal particulars, date of admission, presenting complaint, relevant past history, provisional diagnosis, treatment history and details of laboratory investigations were collected using a properly prepared proforma.,

The Specimens collected were

1) Sequesterectomy/Bone Curettings- dead bone or sequestrae will be there in chronic infection with discharging pus. They are usually collected under general anaesthesia in sterile wide mouthed container during surgery.

2) Sinus Tract Aspirate - collected under local anaesthesia after cleaning the site with fresh normal saline and deeply aspirate pus using syringe and needle

3) Double Swab - taken from depth of wound after cleaning the area with sterile normal saline. Repeated isolation of same organism was only taken ito consideration.

Specimens collected were transported without delay to the lab in wide mouthed containers or in syringe with needle pierced into cork material to maintain anaerobic condition.

III)Processing of specimen

Gross or macroscopic apperance

- $\quad$ sequestrae- dead friable bone piece with surrounding tissue, sometimes associated with foul smell.

- sinus tract aspirate-purulent material sometimes blood stained

- double swab- one swab taken for preparing smear and other used for inoculation in plates

Sequestra is processed by grinding the bone into small pieces with sterile pestle and mortar.

Then specimen is subjected to

1) Gram Staining

Done to find number of pus cells, morphology and gram reaction of bacteria.

2) Culture- Specimen obtained were inoculated into the following media

Blood Agar

Mac Conkey Agar
Salt Agar

Chocolate Agar

Glucose Broth

Robertson's cooked meat media was also inoculated to rule out anaerobic infections.

Inoculated Blood agar plates were streaked with standard strain of Staphylococcus aureus to detect $H$. influenza which shows satellitism around colonies of haemolytic Staphylococcus aureus (a source of $\mathrm{V}$ factor).

Growth on culture plates were identified using their biochemical characterestics.Antibiotic sensitivity pattern of the isolates were also analysed.

3) Antibiotic Sensitivity Testing-

- After identifying the organism- sensitivity test was done by disc diffusion method.Kirby- Baeur method according to CLSI guidelines on Mueller Hinton agar for all the organisms except for Streptococci which was done in blood agar plate.

- The control strains used were Staphylococcus aureus ATCC 25922, Escherichia coli ATCC 35218, Pseudomonas aeruginosa ATCC 27853.

\section{Special Tests}

- D test was performed for Staphylococci which were resistant to Erythromycin

- Iodometry for pencillinase producing staphylococcus species

- Gram negative organisms were tested for ESBL, MBL and Amp-C resistance.

\section{1) Double Disk Diffusion Test (D test) for Staphylococcus aureus}

$\mathrm{D}$ test is performed for the detection of inducible Clindamycin resistance in isolates of that showed in vitro resistance to Erythromycin and susceptibility to Clindamycin.

II) Betalactamase production in Staphylococcus aureus $^{7}$

Iodometry -Staphylococcal Isolates showing MIC $<0.125 \mu \mathrm{g} / \mathrm{ml}$ for Penicillin were tested. 
Hydrolysis of Penicillin yields penicilloic acid, which reduces iodine, decolourising starch-iodine complex. This reaction can be exploited to detect $\beta$-lactamase activity in tubes or on paper strips.study was conducted by tube method.

$\beta$-lactamase activity is indicated by decolourisation of the iodine. These tests are particularly sensitive for staphylococcal penicillinase.

\section{III) Modified Hodge Test for Carbapenemase Detection in Enterobacteriaceae}

Carbapenemase production is detected by the Modified Hodge Test when the test isolate produces the enzyme and allows growth of a carbapenem susceptible strain (E.coli ATCC 25922) towards a carbapenem disk. The result is a characteristic cloverleaf-like indentation.

\section{Interpretation/Results}

After 16-24 hours of incubation, examine the plate for a clover leaf-type indentation at the intersection of the test organism and the E. coli 25922, within the zone of inhibition of the carbapenem susceptibility disk.

\section{Positive test}

Test has a clover leaf-like indentation of the E.coli strain 25922 growing along the test organism growth streak within the disk diffusion zone.

Negative test

Test has no growth of the E.coli25922 along the test organism growth streak within the disc diffusion.

IV) Double Disc Synergy Test (DDST) for ESBL detection $^{8}$

All the strains which showed a diameter of less than $27 \mathrm{~mm}$ for Cefotaxime and less than $25 \mathrm{~mm}$ for Ceftriaxone, were selected for checking the ESBL production.

Procedure

The ESBL production was tested by the Modified Double Disc Synergy Test (MDDST) by using a disc of Amoxicillin-Clavulanate $(20 / 10 \mu \mathrm{g})$ along with four cephalosporins;

$3^{\text {rd }}$ generation cephalosporins-Cefotaxime, Ceftriaxone, Cefpodoxime and fourth genarationCefepime.
Klebsiella pneumonia ATCC 700603 was used as a control strain for a positive ESBL production and Escherichia coliATCC25922 was used as a negative control for the ESBL production.

V) MBL detection in Pseudomonas aeruginosa Resistance to Imipenem (IMP), Meropenem (MER) and Ceftazidime (CAZ) was determined by Kirby Bauer disc diffusion testing with CAZ $(30 \mu \mathrm{g})$, IMP $(10 \mu \mathrm{g})$, and MER $(10 \mu \mathrm{g})$. The zones of inhibition were interpreted as per CLSI (M100$\mathrm{S} 15)$. The quality control strains used for the study were Escherichia coli ATCC 25922 and Pseudomonas aeruginosa ATCC 27853.

\section{Screening for and confirmation of MBLs}

The strains resistant to Ceftazidime and carbapenems were screened for MBL by Combined Disk diffusion Test using Ceftazidime $(30 \mu \mathrm{g})+5 \mathrm{ml}-0.5 \mathrm{M}$ EDTA $(930 \mathrm{mg})$, Imipenem $(10 \mu \mathrm{g})+5 \mathrm{ml}-0.5 \mathrm{M}$ EDTA(930mg) and Meropenem $(10 \mu \mathrm{g})+5 \mathrm{ml}-0.5 \mathrm{M}$ EDTA(930mg). An increase of $7 \mathrm{~mm}$ or more in zone diameter in the presence of EDTA compared to those with Imipenem, Meropenem or Ceftazidime tested alone was considered to be a positive test for the presence of an MBL.

\section{VI) Amp C Detection}

All the isolates which showed a synergistic effect with cefepime only in MDDST were further tested for the AmpC enzyme production by AmpC disc test after an initial screening with a Cefoxitin (30 $\mu g)$ disc.

\section{Antibiotic Discs used for each Organism Testing}

Staphylococcus aureus

- Pencillin (10IU), Gentamicin (10 $\mu \mathrm{g})$,

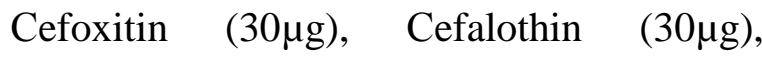
Erythromycin $(15 \mu \mathrm{g})$, Amikacin $(30 \mu \mathrm{g})$, Vancomycin $(30 \mu \mathrm{g})$, Linezolid $(30 \mu \mathrm{g})$, Oxacillin $(1 \mu \mathrm{g})$, Clindamycin $(2 \mu \mathrm{g})$,

For Streptococcus

Penicillin(10 IU), Gentamicin $(10 \mu \mathrm{g})$,
Bacitracin $(0.04 \mathrm{U}), \quad$ Cefalothin $(30 \mu \mathrm{g})$,
Erythromycin $(15 \mu \mathrm{g})$, Amikacin $(30 \mu \mathrm{g})$,
Vancomycin $(30 \mu \mathrm{g})$, Clindamycin $(2 \mu \mathrm{g})$ 
For testing Enterococcus

- Penicillin (10 IU), Gentamicin $(10 \mu \mathrm{g})$, Erythromycin $(15 \mu \mathrm{g}), \quad$ Ampicillin $(10 \mu \mathrm{g})$, Vancomycin $(30 \mu \mathrm{g})$, Linezolid $(30 \mu \mathrm{g})$

For Enterobacteriaceae

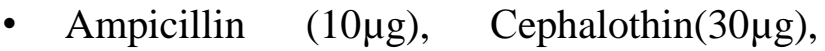
Cefuroxime $(30 \mu \mathrm{g})$, Gentamicin $(10 \mu \mathrm{g})$, Amikacin $\quad(30 \mu \mathrm{g}), \quad$ Cotrimoxazole $(1.25 / 23.75 \mu \mathrm{g}), \quad$ Ciprofloxacin $(5 \mu \mathrm{g}), \quad$ Cefepime $(30 \mu \mathrm{g}), \quad$ Ceftriaxone $(30 \mu \mathrm{g})$, Cefotaxime $(30 \mu \mathrm{g})$,

- Ceftazidime $(30 \mu \mathrm{g})$, PiperacillinTazobactum $(100 / 10 \mu \mathrm{g}) \quad$ Cefoperazone Sulbactum $(75 / 30 \mu \mathrm{g})$.
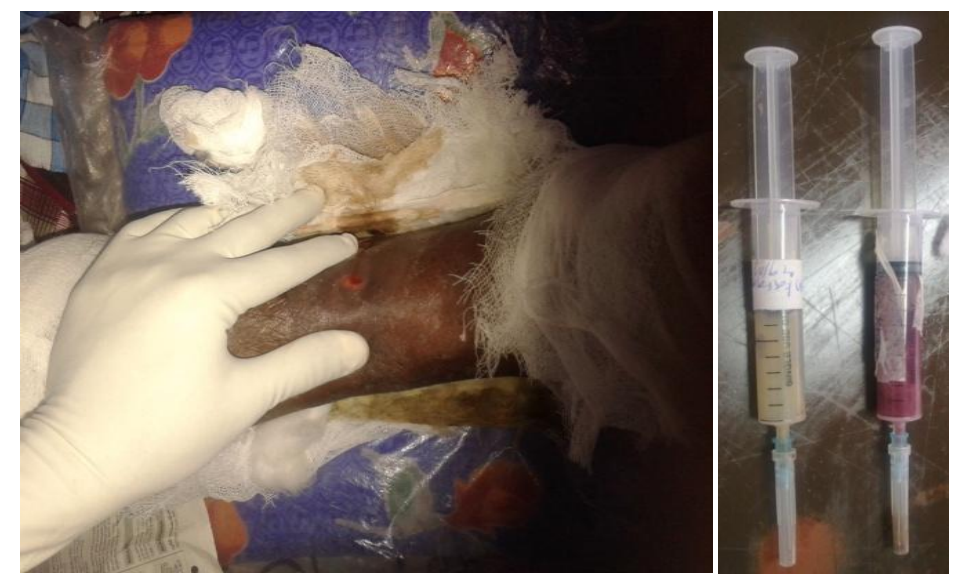

1.Specimen Collection From Sinus Tract Aspirate
For testing Pseudomonas aeruginosa

Cotrimoxazole $(1.25 / 23.75 \mu \mathrm{g})$, Tobramycin $(10 \mu \mathrm{g}), \quad$ Netilmicin $\quad(30 \mu \mathrm{g}) \quad$ Piperacillin Tazobactum (100/10 $\mu \mathrm{g}) \quad$ Cefaperazone Sulbactum $(30 \mu \mathrm{g}), \quad$ Aztreonam $(30 \mu \mathrm{g})$, Cefotaxime $(30 \mu \mathrm{g})$

\section{For Gram Negative Resistant Organisms}

- Imipenem $(10 \mu \mathrm{g}), \quad$ Meropenem $(10 \mu \mathrm{g})$, Ertapenem $\quad(10 \mu \mathrm{g}) \quad$ Polymyxin $(10 \mu \mathrm{g})$, Tigecycline $(15 \mu \mathrm{g})$, EDTA-Imipenem $(10 \mu \mathrm{g})$ Culture reports were issued and the orthopaedic surgeons were informed about the isolates identified and their antibiotic sensitivity pattern. Immediate follow up of patients who were on treatment was done for a period of 6 month.

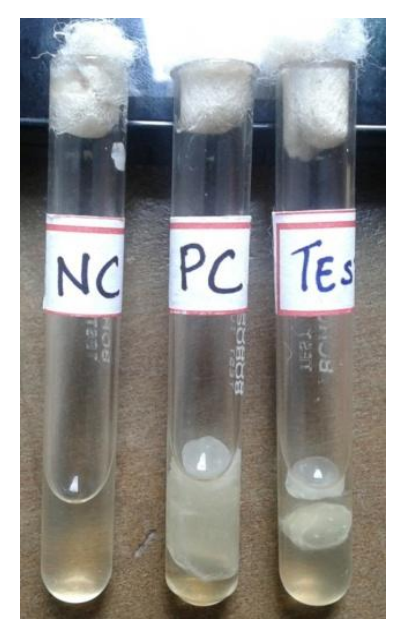

2.Tube Coagulase Test

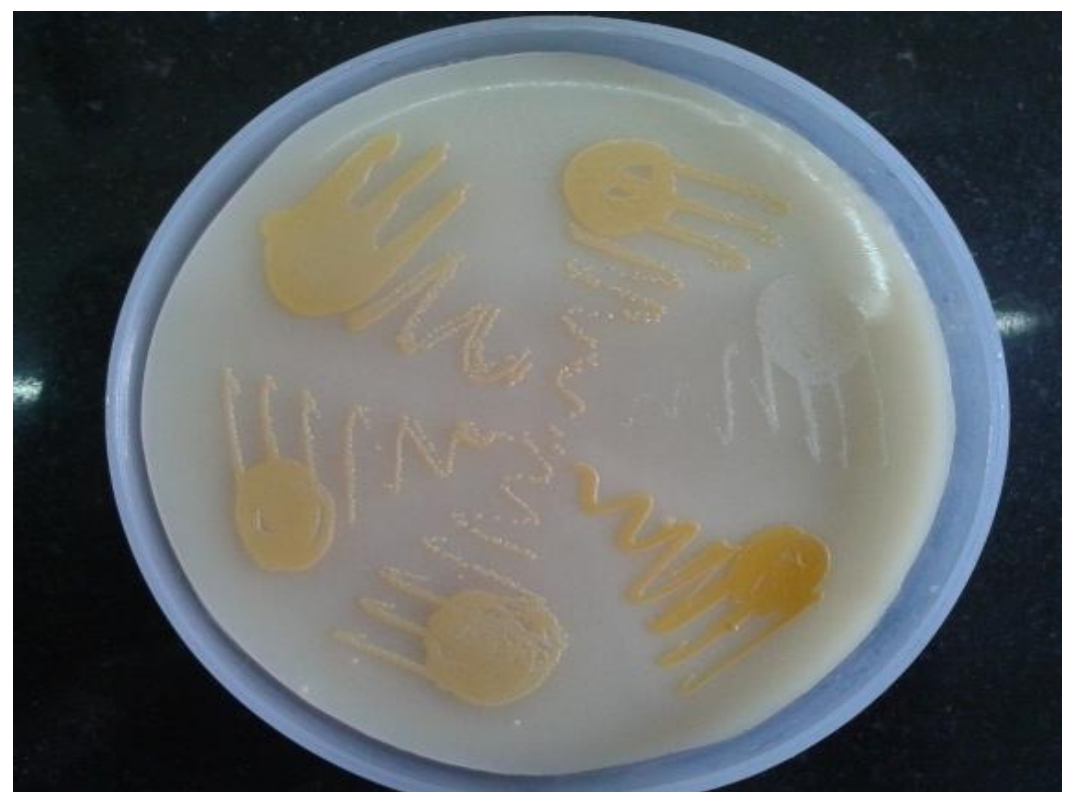

3. Staphylococcus Aureus on Salt Milk Agar 


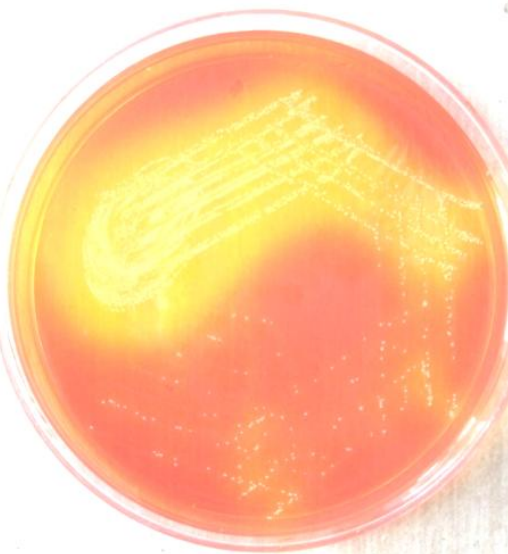

4. Mannitol Salt Agar-Staphylococcus Aureus

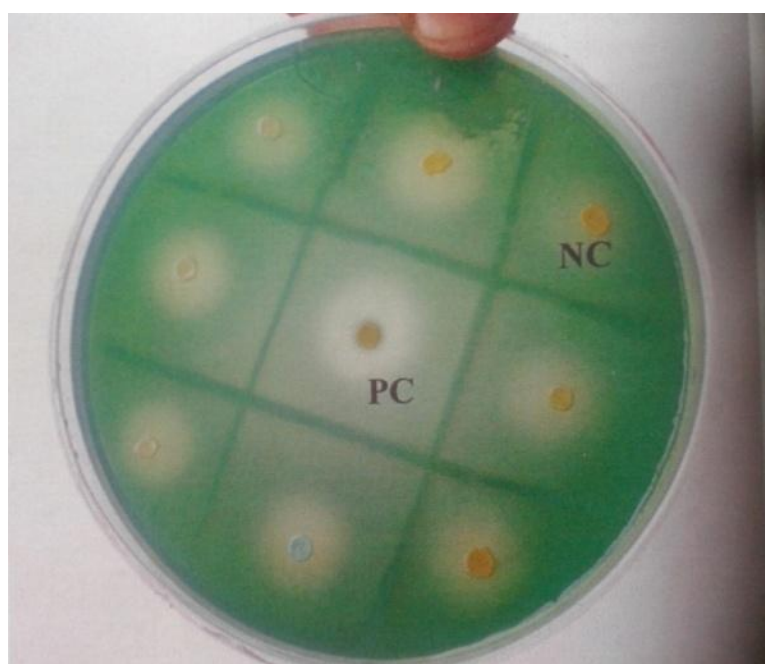

6. DNAase Test For Staphylococcus

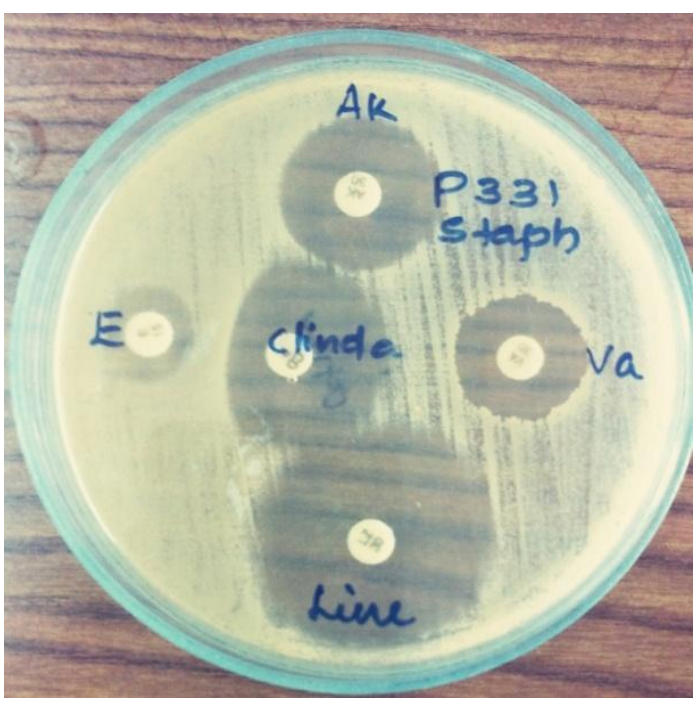

8 D Test- Erythromycin Induced Clindamycin Resistance

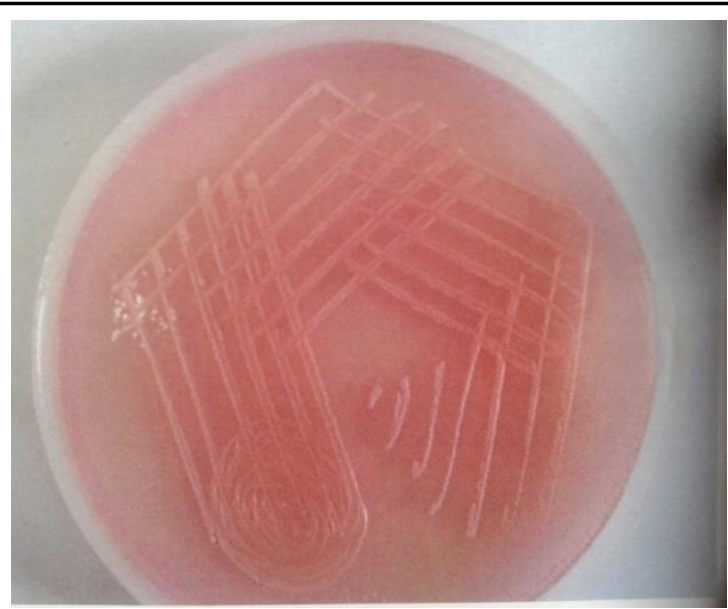

5.Phosphatase Test- Staphylococcus Aureus

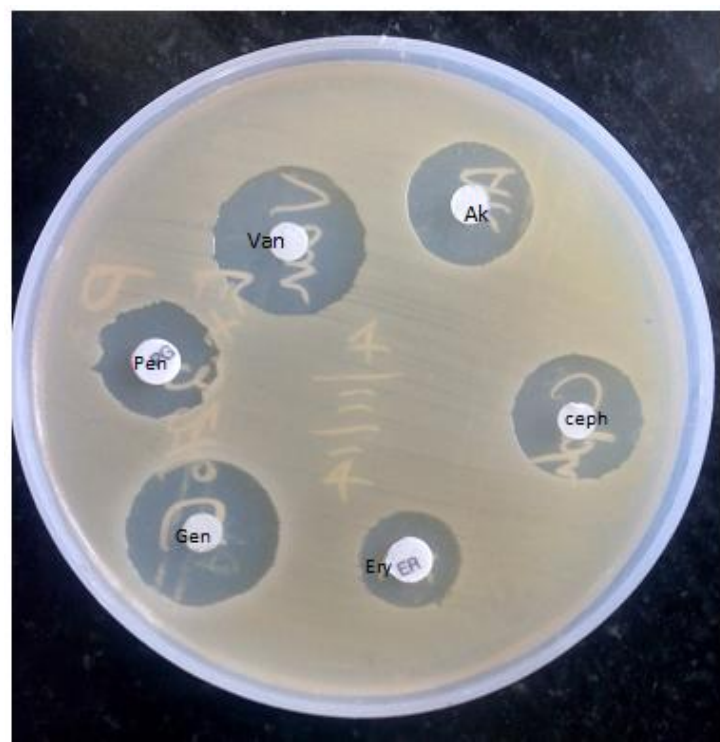

7. Antibiotic Sensitivity Pattern of Staphylococcus Aureus

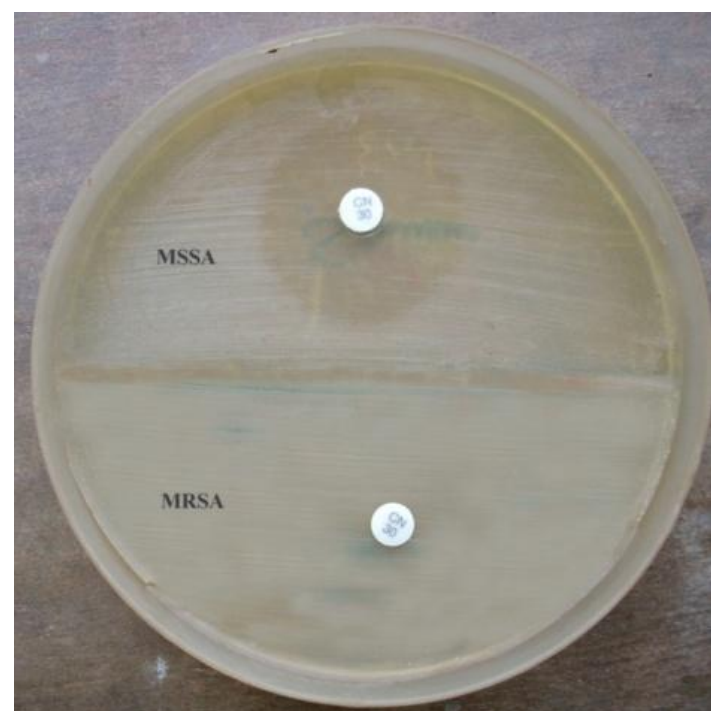

9.Cefoxitin Sensitivity of MSSA\& MRSA 


\section{JMSCR Vol||06||Issue||04||Page 858-874||April}
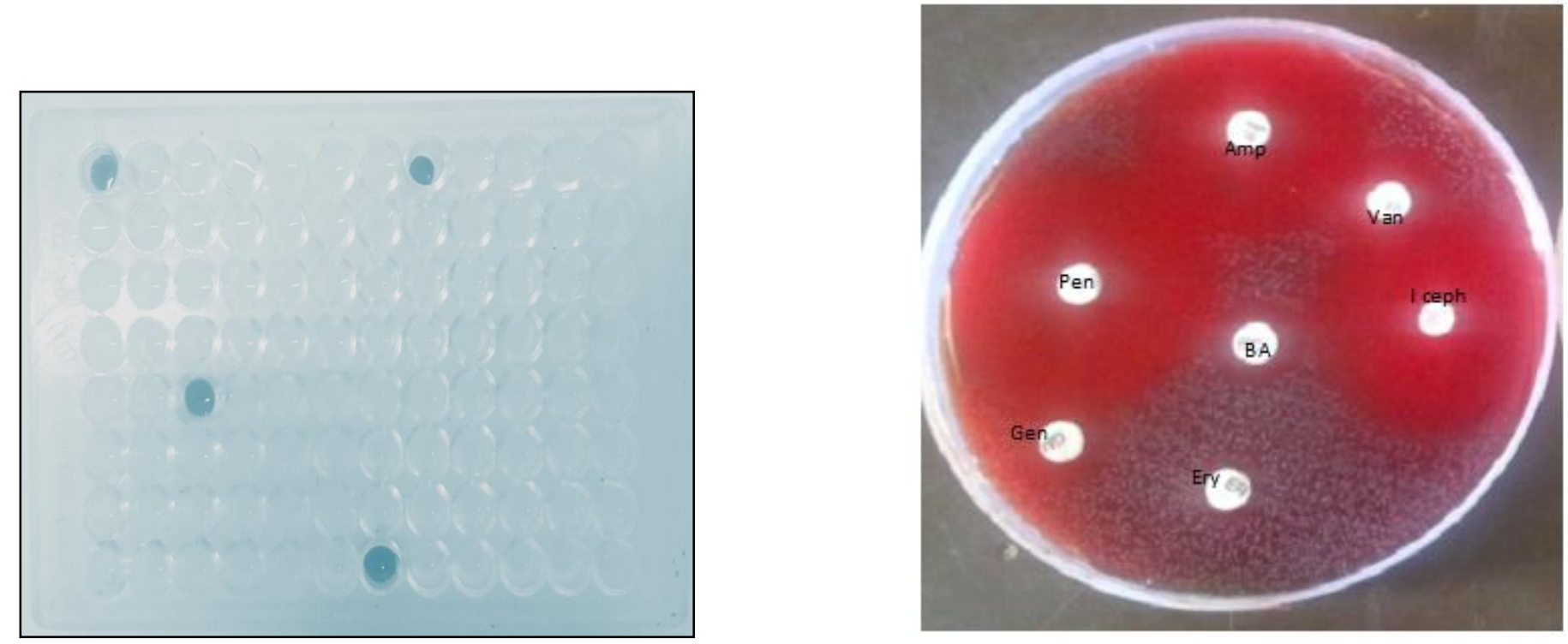

10.Iodometry

11.Antibiotic Sensitivity Pattern Of Beta Hemolytic Streptococci

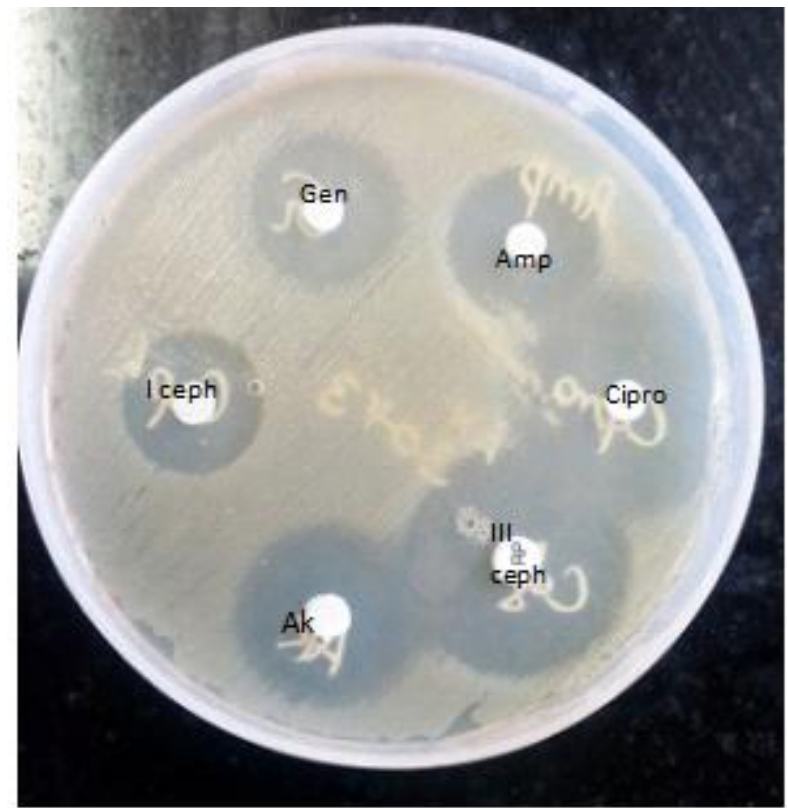

12.Antibiotic Sensitivity Pattern of E.Coli

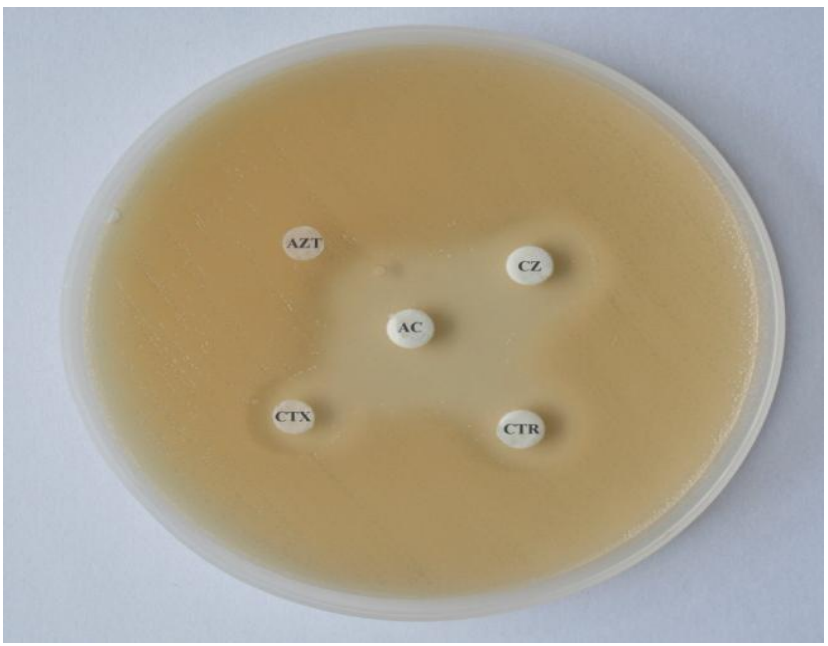

13. ESBL Production in Gram Negative Bacteria

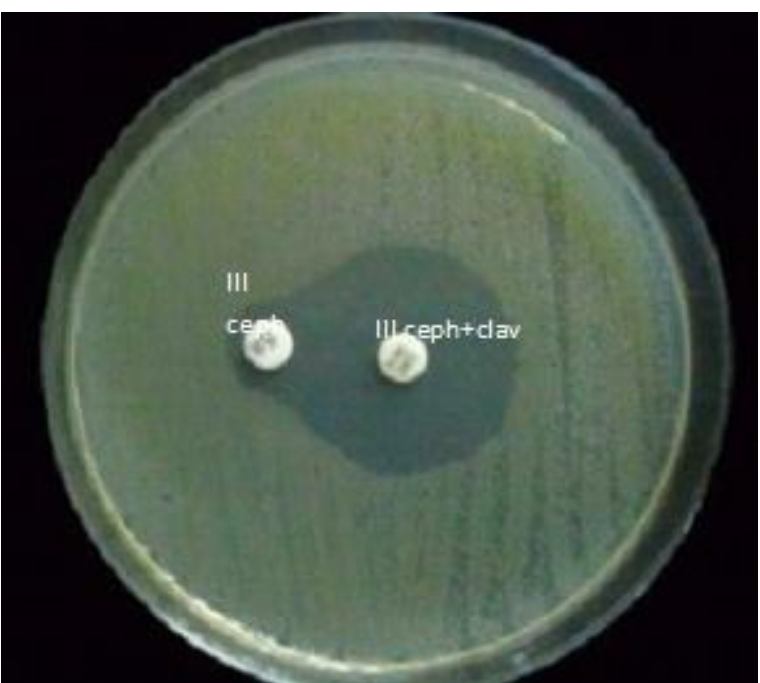

14. Double Disk Synergy Test 


\section{Observation and Results}

The study was conducted in the Department of Microbiology and Department of Orthopaedics from July 2013 to June 2014. As per the inclusion and exclusion criteria 150 patients with chronic osteomyelitis following compound fracture participated in the study.

\section{Type of Specimen Collected}

\section{Table-I}

\begin{tabular}{|l|c|c|}
\hline TYPEOF SPECIMEN & $\begin{array}{c}\text { NUMBER OF SPECIMENS } \\
\text { COLLECTED }\end{array}$ & $\begin{array}{c}\text { PERCENTAGE } \\
\%\end{array}$ \\
\hline BONE CURETTINGS & 14 & 9.3 \\
\hline SINUS TRACT ASPIRATE & 136 & 90.7 \\
\hline TOTAL & 150 & 100 \\
\hline
\end{tabular}

Figure-I

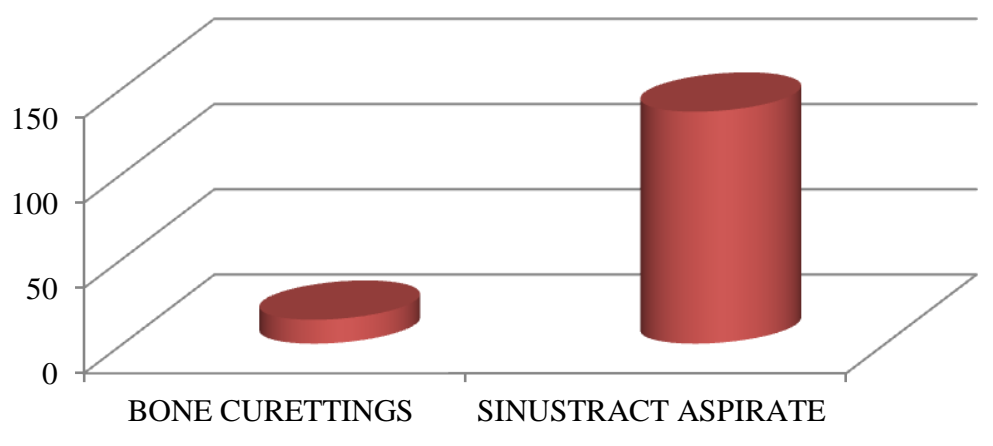

A total of 150 specimens were collected and most frequent mode of collection was sinus tract aspiration.

1) Age and Sex wise Distribution of Cases

Table-2

\begin{tabular}{|c|c|c|}
\hline AGE & $\begin{array}{c}\text { NUMBER OF } \\
\text { CASES(percentage) } \\
\text { MALE }\end{array}$ & FEMALE \\
\hline $20-29$ & $20(18 \%)$ & $12(30.8 \%)$ \\
\hline $30-39$ & $28(25.2 \%)$ & $5(12.8 \%)$ \\
\hline $40-49$ & $23(20.7 \%)$ & $13(33.3 \%)$ \\
\hline $50-59$ & $18(16.2 \%)$ & $5(12.8 \%)$ \\
\hline $60-69$ & $13(11.7 \%)$ & $2(5.1 \%)$ \\
\hline $70-79$ & $7(6.3 \%)$ & $2(5.1 \%)$ \\
\hline $80-89$ & $2(1.8 \%)$ & 0 \\
\hline TOTAL & 111 & 39 \\
\hline
\end{tabular}


Figure-2

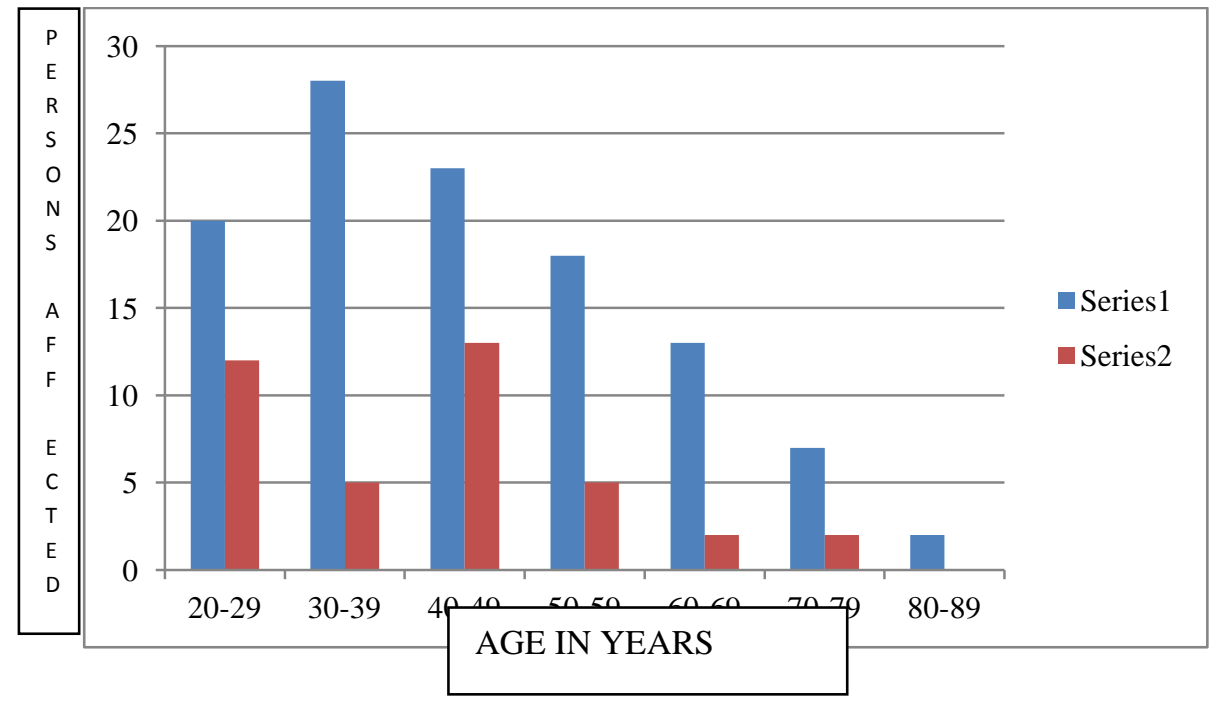

About 111 males and 39 females were included in the study. The maximum number of patients were in the active age group 40 to 49 years. The maximum number of males affected $(25.2 \%)$ were in the age group 30-39 years and maximum number of females affected were in the age group 40- 49 years $(33.3 \%)$.

\section{2) Analysis of Causative Factors of Chronic Osteomyelitis}

\section{Table-3}

\begin{tabular}{|l|c|c|}
\hline CAUSES & NUMBER OF CASES & PERCENTAGE \\
\hline $\begin{array}{l}\text { FRACTURE ASSOCIATED WITH ROAD } \\
\text { TRAFFIC ACCIDENTS }\end{array}$ & 140 & 93.3 \\
\hline OTHERS & 10 & 6.7 \\
\hline TOTAL & 150 & 100 \\
\hline
\end{tabular}

Figure-3

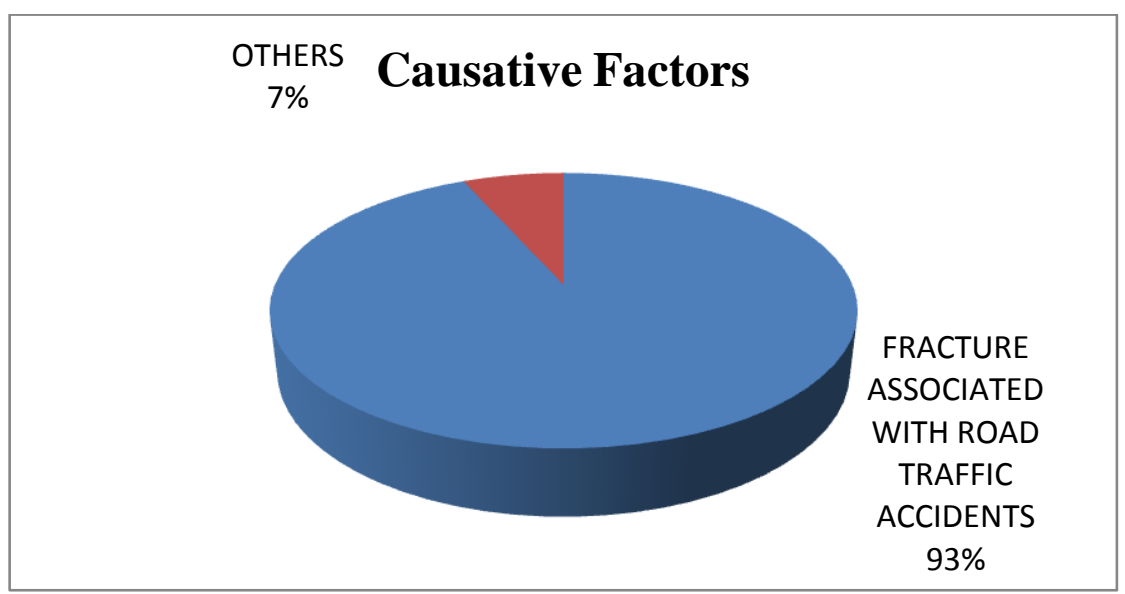

Among 140 cases of fracture associated with chronic osteomyelitis 122 cases $(93 \%)$ were due to road traffic accidents and 18 cases were due to fall. Others were due to needle prick injury, bone related disorders like osteoporosis etc. 
4) Distribution of Cases According to Type of Fracture

Table-4

\begin{tabular}{|l|c|c|}
\hline TYPE OF FRACTURE & DISTRIBUTION OF CASES & PERCENTAGE (\%) \\
\hline OPEN FRACTURE & 114 & 76 \\
\hline CLOSED FRACTURE & 36 & 24 \\
\hline TOTAL & 150 & 100 \\
\hline
\end{tabular}

Figure-4

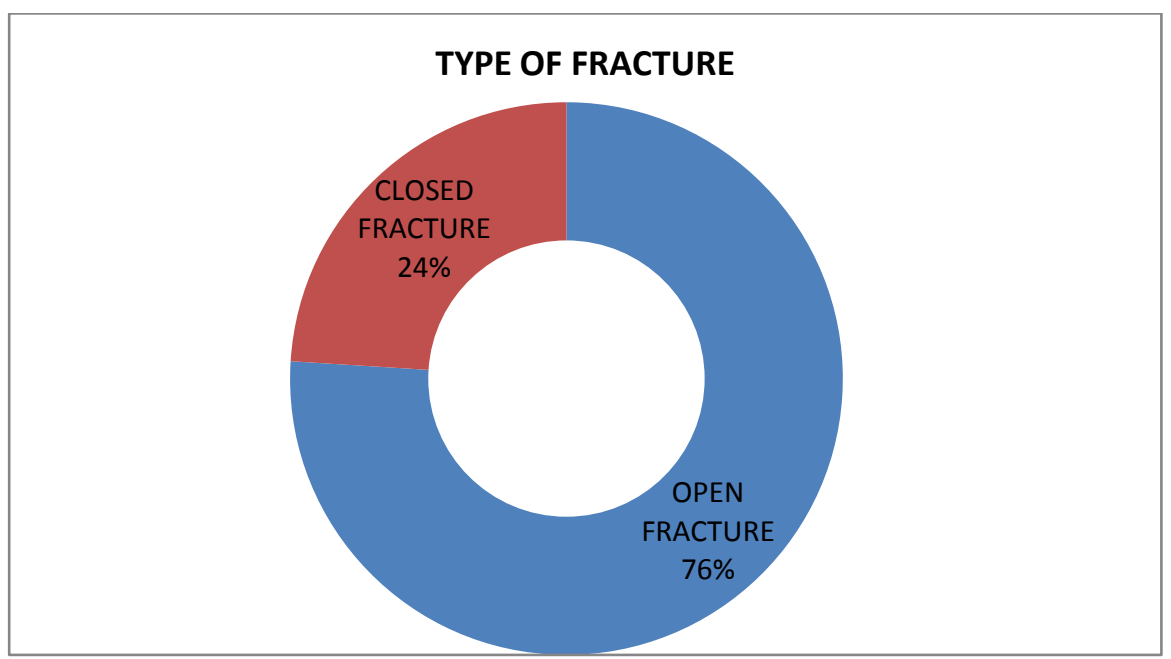

Majority of fractures which resulted in chronic osteomyelitis were open compound fractures.

5) Distribution of Cases According to Bones Involved in Fracture

Table-5

\begin{tabular}{|l|c|c|}
\hline BONES INVOLVED & NUMBER OF CASES & PERCENTAGE (\%) \\
\hline FEMUR & 66 & 44 \\
\hline TIBIA & 29 & 19.3 \\
\hline BOTH BONE LOWER LIMB & 40 & 26.7 \\
\hline ANKLE & 2 & 1.3 \\
\hline METATARSAL & 2 & 1.3 \\
\hline HUMERUS & 2 & 1.3 \\
\hline RADIUS & 1 & 0.67 \\
\hline BOTH BONE UPPER LIMB & 4 & 2.6 \\
\hline METACARPAL & 1 & 0.67 \\
\hline SKULL & 3 & 2 \\
\hline TOTAL & 150 & 100 \\
\hline
\end{tabular}


Figure-5

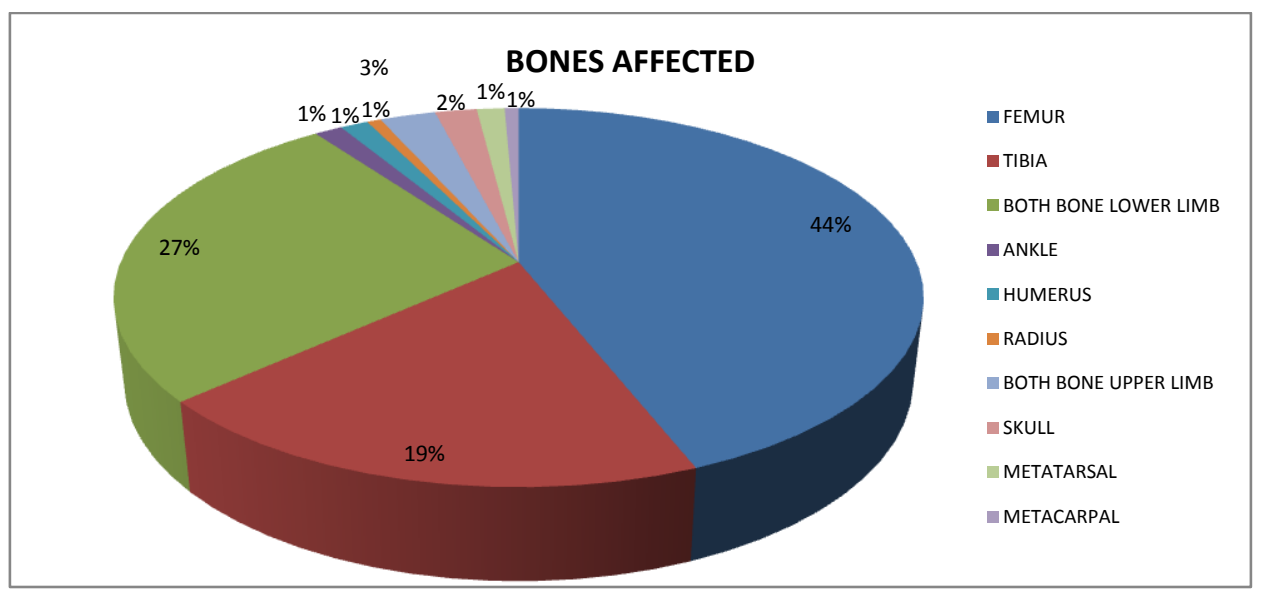

Most common bone affected was femur(44\%).Bones of lower limb were commonly affected (92\%) than upper limb.

\section{6) Distribution of Cases According to Stage of Fracture}

\section{Table-6}

\begin{tabular}{|l|c|}
\hline BONE & STAGE OF FRACTURE \\
\hline SKULL & 4 \\
\hline HUMERUS & 3 \\
\hline RADIUS & 3 \\
\hline ULNA & 3 \\
\hline METACARPAL & 3 \\
\hline FEMUR & 4 \\
\hline TIBIA & 4 \\
\hline BOTHBONES LOWERLIMB & 3 \\
\hline METATARSAL & 3 \\
\hline
\end{tabular}

\section{Figure-6}

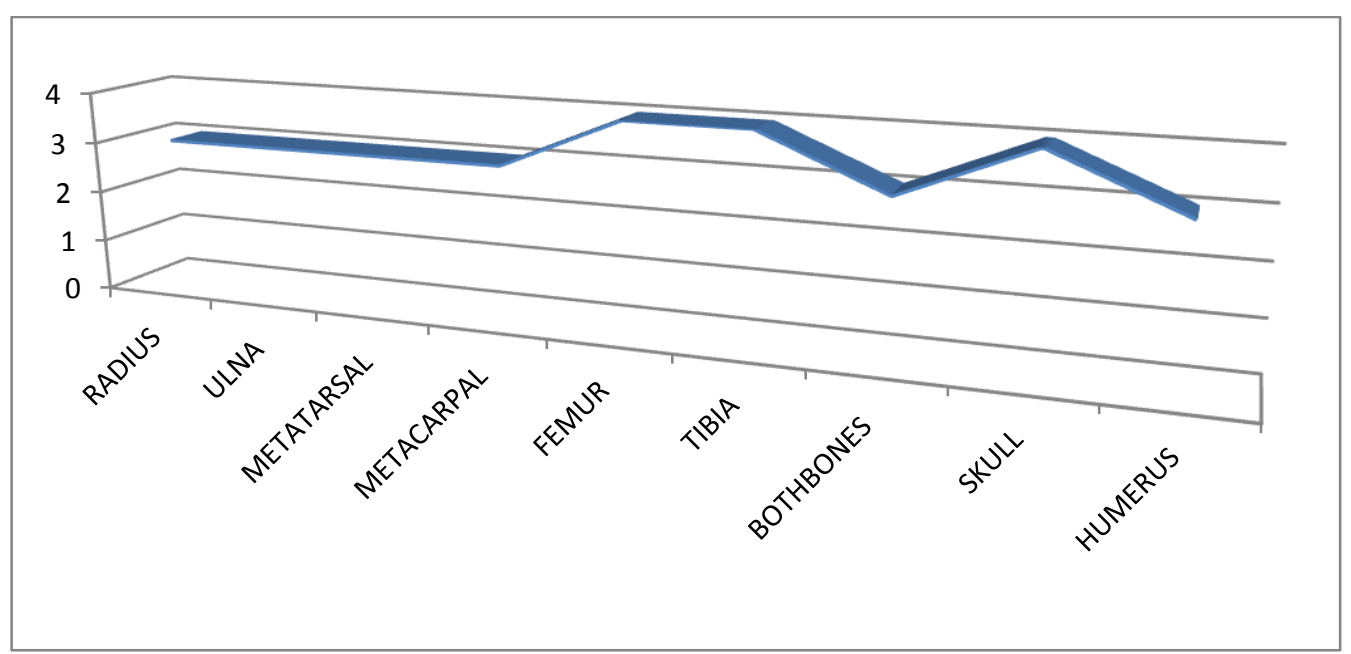

Of the total number of cases, fractures which involved long bones of lower limb like femur and tibia and fractures of skull were of higher stage compared to fractures of small bones and bones of upper limb. 


\section{7) Analysis of Cases According to Culture Positivity}

Table-7

\begin{tabular}{|l|c|c|}
\hline FINDINGS & NUMBER OF CASES & PERCENTAGE \\
\hline Culture positive & 58 & 38.7 \\
\hline Sterile & 92 & 61.3 \\
\hline TOTAL & 150 & 100 \\
\hline
\end{tabular}

\section{Figure-7}

Culture Positivity

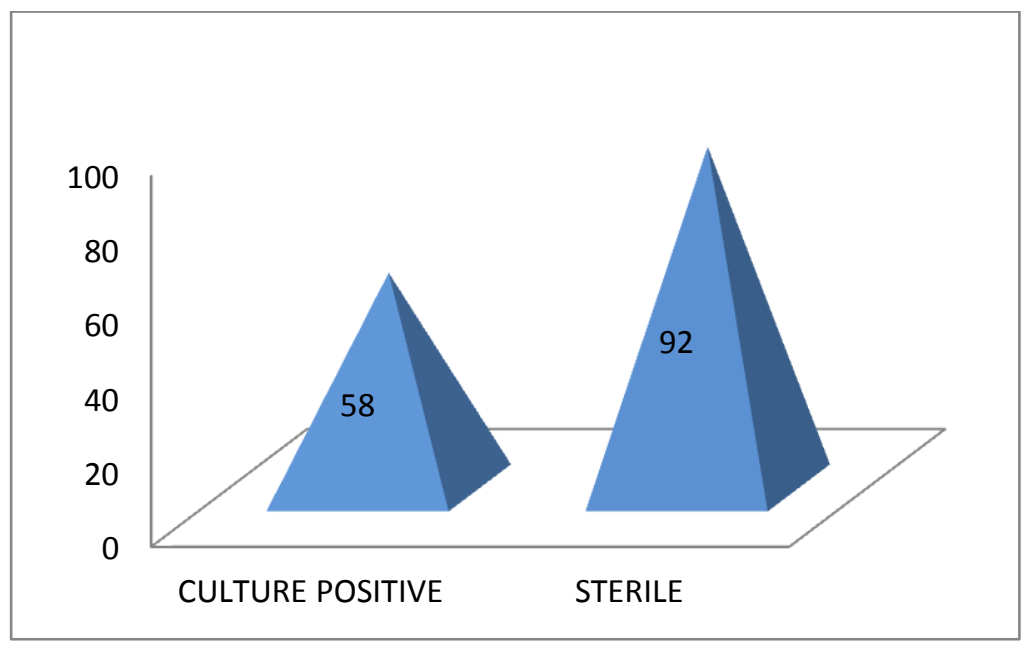

Out of 150 cases studied 58 cases were culture positive while the rest were bacteriologically sterile.

\section{8) Analysis of Total Isolates}

\section{Table-8}

\begin{tabular}{|l|c|c|c|}
\hline SL NO & ISOLATES & NUMBER & PERCENTAGE(\%) \\
\hline 1 & Gram positive isolates & 39 & 67.2 \\
\hline 2 & Gram negative isolates & 19 & 32.8 \\
\hline TOTAL & & 58 & 100 \\
\hline
\end{tabular}

\section{Figure-8}

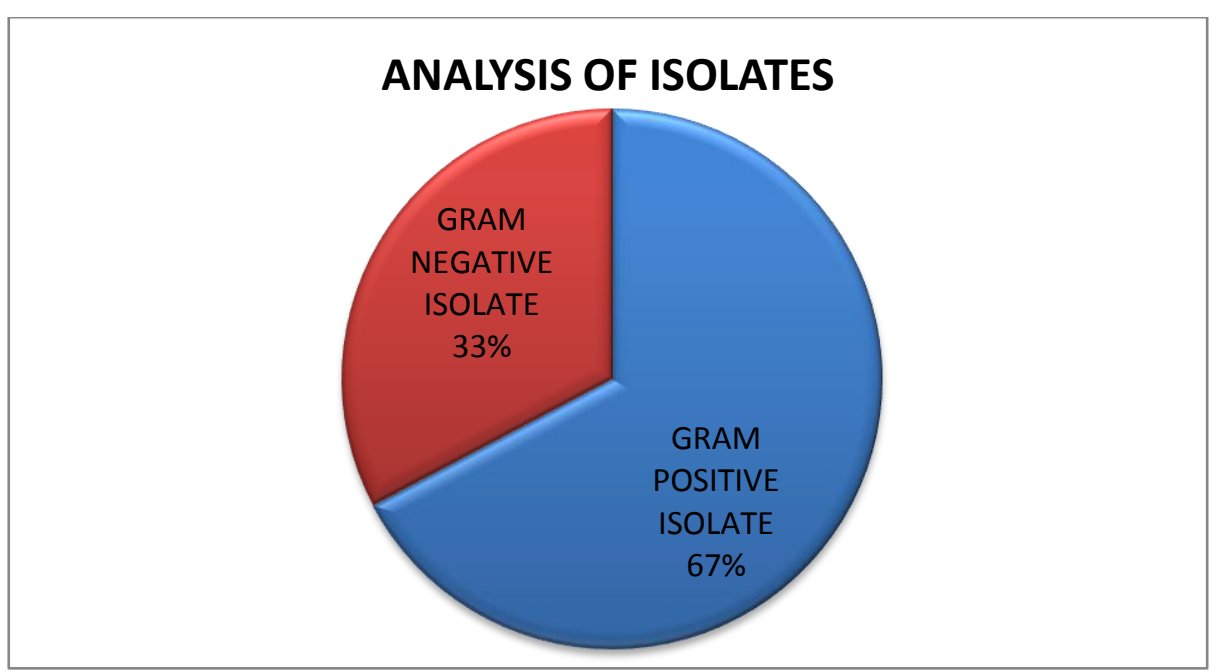

Gram positive isolates (67.2\%) were more compared to gram negative isolates $(32.8 \%)$. 


\section{9) Analysis of Gram positive Isolates}

Table-9

\begin{tabular}{|l|c|c|c|}
\hline ORGANISM & SENSITIVE & RESISTANT & $\begin{array}{c}\text { TOTAL } \\
\text { ( PERCENTAGE) }\end{array}$ \\
\hline Staphylococci & 28 (MSSA) & 8 (MRSA) & $36(92.3)$ \\
\hline Streptococcus pyogenes & 1 & 0 & $1(2.6)$ \\
\hline Enterococcus feacalis & 1 & 0 & $1(2.6)$ \\
Enterococcus raffinosus & 1 & 0 & $1(2.6)$ \\
\hline TOTAL & 31 & 8 & $39(100)$ \\
\hline
\end{tabular}

Figure-9

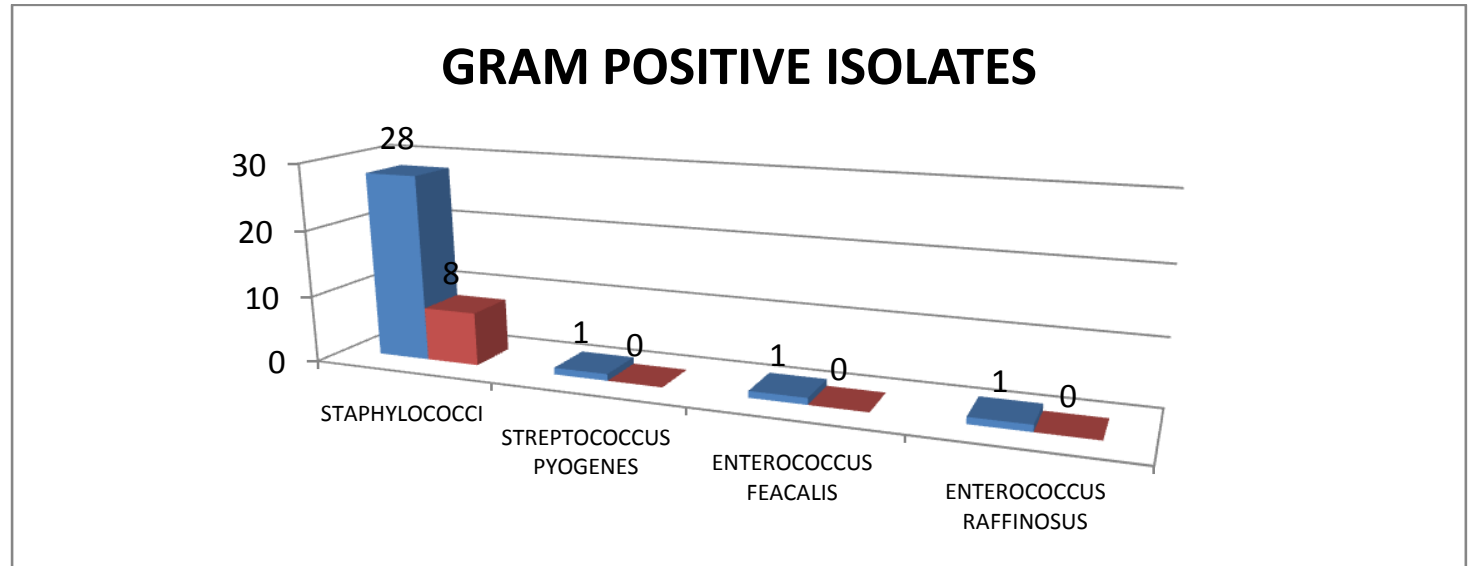

Among gram positive isolates $92 \%$ was Staphylococcus aureus with 2\% MRSA isolates.

10) Analysis of Gram Negative Isolates

Table-10

\begin{tabular}{|c|c|c|c|}
\hline ORGANISM & SENSITIVE & RESISTANT & TOTAL ( \%PERCTGE) \\
\hline Klebsiella pneumoniae & 6 & 2 & $8 \quad(42.4)$ \\
\hline Acinetobacter spp & 3 & 1 & $4 \quad(21)$ \\
\hline Pseudomonas spp & 2 & 0 & $2(10.5)$ \\
\hline E.coli & 2 & 1 & $3(15.7)$ \\
\hline Proteus mirabilis & 1 & 0 & $1 \quad(5.2)$ \\
\hline Proteus vulgaris & 1 & 0 & $1 \quad(5.2)$ \\
\hline TOTAL & 15 & 4 & 19 \\
\hline
\end{tabular}


Figure-10
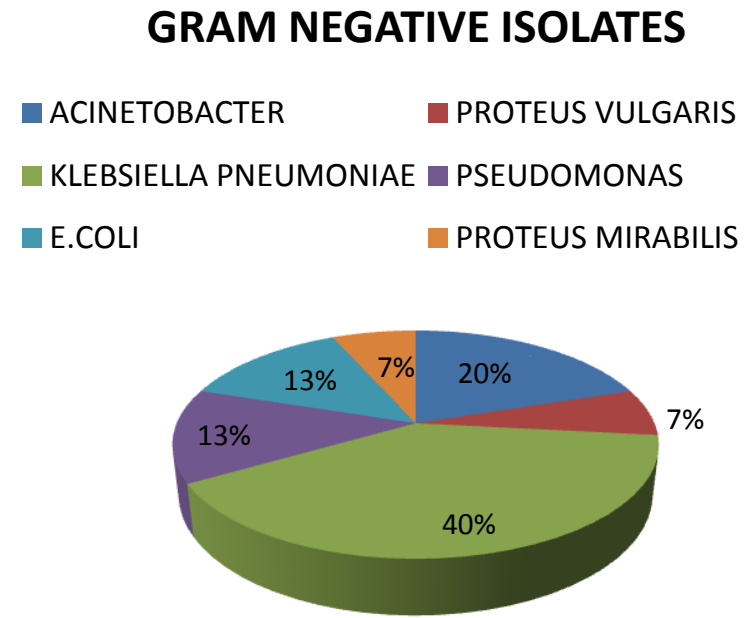

Major gram negative isolate was Klebsiella species followed by Acinetobacter spp and E.coli.

\section{1) Analysis of Polymicrobial Isolates}

Table-11

\begin{tabular}{|l|r|c|}
\hline SL.NO & POLYMICROBIAL INFECTION & ISOLATES \\
\hline 1 & Staphylococcus+Beta Hemolytic Streptococci+Klebsiella spp & 1 \\
\hline 2 & MRSA+Klebsiella spp & 2 \\
\hline 3 & Staphylococcusaureus +Klebsiella spp & 2 \\
\hline 4 & MRSA+MDR E.coli & 1 \\
\hline 5 & MRSA+Proteus.vulgaris & 1 \\
\hline 6 & Klebsiella spp+Enterococcus feacalis & 1 \\
\hline TOTAL & & 7 \\
\hline
\end{tabular}

Figure-11

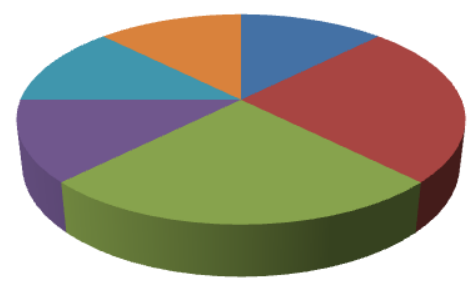

- Staphylococcus+Beta Hemolytic Streptococci+Klebsiella spp

- MRSA+Klebsiella spp

- Staphylococcus aureus +Klebsiella spp

MRSA+MDR E.coli

MRSA +Proteus.vulgaris

Klebsiella spp+Enterococcus feacalis

Out of the 7 polymicrobial cases-Klebsiella pneumoniaewith Staphylococcus aureus was the main pathogen. 
12) Antibiotic Sensitivity Pattern of Gram Positive Isolates (\% Sensitive)

\section{Table-12}

\begin{tabular}{|l|l|l|l|l|l|l|l|l|l|l|l|l|}
\hline ORGANISM & Pen & Amp & Gen & Ery & Ceph I & Amk & Van & Ceph III & Rif & Clin & Lin & Ba \\
\hline Staphylococcus aureus (28) & 40 & NT & 95 & 45 & 100 & 100 & 100 & 100 & NT & NT & NT & NT \\
\hline MRSA(8) & 0 & NT & 12 & 12 & 0 & 25 & 100 & 100 & 100 & 100 & 100 & NT \\
\hline Streptococcus pyogenes(1) & 100 & 100 & $100-(\mathrm{I})$ & 100 & 100 & NT & NT & NT & NT & NT & NT & 100 \\
\hline Enterococcus(2) & 0 & 50 & $100-(\mathrm{I})$ & 50 & NT & NT & 0 & NT & NT & NT & 0 & NT \\
\hline
\end{tabular}

I-Intermediate Pen- Penicillin Gen- Gentamicin

Ery-Erythromycin Ceph III-Third generation cephalosporins

Ceph I- first generation cephalosporin AmkAmikacin Van-Vancomycin Clin-Clindamycin Rif- Rifampicin Lin-Linezolid Ba-Bacitracin NT-Not tested
Of the 28 isolates of Staphylococcus aureus, $40 \%$ were resistant to Penicillin. 8 isolates were MRSA .There were two isolates of EnterococcusEnterococcus feacalis, Enterococcus raffinosus.

Enterococcus raffinosus showed resistance to Ampicillin, Gentamicin and Erythromycin but was sensitive to Vancomycin and Linezolid., speciated by VITEK 2.

\section{3) Antibiotic Sensitivity Pattern of Gram Negative Isolates}

\section{Table-13}

\begin{tabular}{|l|c|c|c|c|c|c|c|c|c|}
\hline ORGANISM & Amp & Gen & I Ceph & Amk & Cipro & $\begin{array}{c}\text { III } \\
\text { Ceph }\end{array}$ & $\begin{array}{c}\text { Cefo+ } \\
\text { Sul }\end{array}$ & $\begin{array}{c}\text { Pip+ } \\
\text { Taz }\end{array}$ & $\begin{array}{c}\text { Imi } \\
\text { Kleb.pneumoniae (8) }\end{array}$ \\
\hline Acinetobacter baumanii(4) & 25 & 60 & 30 & 30 & 30 & 30 & 100 & NT & 100 \\
\hline E.coli(3) & 0 & 33 & 33 & 33 & 33 & 100 & 100 & NT & 100 \\
\hline Pseudomonas aeruginosa(2) & NT & 50 & NT & 100 & 100 & 100 & NT & 100 & 100 \\
\hline Proteus vulgaris(1) & 0 & 100 & 100 & 100 & 100 & 100 & 100 & NT & 100 \\
\hline Proteus Mirabilis(1) & 0 & 100 & 100 & 100 & 100 & 100 & NT & NT & NT \\
\hline
\end{tabular}

\section{Amp-Ampicillin Gen-Gentamicin Ery-} Erythromycin Amk-AmikacinCeph I-First generation cephalosporins Imi-Imipenem Pip+tazPiperacillin+TazobactumCipro-Ciprofloxacin

\section{Table-14}

\section{Distribution of Multidrug Resistant Gram Negative Isolates}

\begin{tabular}{|l|c|c|}
\hline ORGANISM & TOTAL & ESBL \\
\hline Klebsiella pneumoniae & 8 & 1 \\
\hline Acinetobacter spp & 4 & 1 \\
\hline Pseudomonas spp & 2 & 0 \\
\hline E.coli & 3 & 0 \\
\hline Proteus mirabilis & 1 & 0 \\
\hline Proteus vulgaris & 1 & 0 \\
\hline TOTAL & 19 & 2 \\
\hline
\end{tabular}

Among gram negative isolates, 2 isolates were extended spectrum beta lactamase producing. These were detected by modified hodge test and
Cefo+Sul-Cefoperazone+Sulbactum III CephThird generation Cephalosporin NT- Not tested. Among gram negative isolates Klebsiella pneumoniae subspecies pneumonia was the major isolate. confirmed by double disc synergy testing. no MBL isolates were there. 


\section{Follow Up}

About 66 cases were followed up for a period for 6 months. Total cure rate was 70.6\%. Among follow up cases in 2 of them MRSA was isolated. About 6 cases cured following combination therapy with Vancomycin- Amikacin, Vancomycin- Linezolid, Clindamycin alone. The treatment was given as parenteral therapy for 10 days followed by 2-3 weeks of oral treatment. About $6 \%$ cases did not cure following treatment for 6 months.

\section{Summary and Conclusion}

This study was conducted to identify the aerobic bacterial pathogens of chronic osteomyelitis, their antibiotic sensitivity pattern and to evaluate the outcome and prognosis of patients with chronic osteomyelitis .Long term post operative follow up is essential in determining the effectiveness of treatment. The conclusions of this study are as follows:-

1) The most common cause of chronic osteomyelitis was post traumatic, fracture associated with road traffic accidents. Males in the age group 20 to 39 were predominantly affected.

2) The presence of an orthopaedic implant was found to be a major risk factor in our study.

3) Lower limb bones were commonly affected than the upper limb bones and higher stage fractures were more prone for chronic osteomyelitis. In this study, the association of open fracture with chronic osteomyelitis was found to be more than closed fracture.

4) Staphylococcus aureus accounted for $31.5 \%$ of the chronic osteomyelitis followed by MRSA, Klebsiella aerogenes, Pseudomonas aeruginosa, Beta haemolytic Streptococci and polymicrobial infections

5) In contrast to previous study conducted in this same tertiary centre 6 years ago, a marked decrease in MRSA has occurred because of the establishment of better containment facilities for MRSA infection like separate isolation ward, hand washing and other aseptic precautions, creating awareness among the hospital staff regarding
MRSA and appropriate and adequate antibiotic therapy.

6) ESBL producing isolates showed the emergence of drug resistant pathogens due to antibiotic misuse at the primary level of management of bone fractures.

7) After follow up of these cases for 6 months, cure rate was higher in our study about $70.6 \%$ who were given proper antibiotic therapy along with surgical treatment.

The treatment strategy followed in Medical college hospital, Thiruvananthapuram was a combination of thorough surgical debridement, dead space management by antibiotic beads, bone grafting, limb reconstructive surgery and antimicrobial therapy.

So steps should be taken to prevent the emergence of multi drug resistant strains. This study also reveals that the surgical procedures under strict aseptic precautions and antibiotic therapy according to culture and sensitivity and early removal of implant in post traumatic osteomyelitis can reduce the incidence of amputation.

Since this is a chronic disease the progress of the disease has a significant impact on patient's psychosocial, physical and economical life. Therefore all healthcare professionals including surgeons, nurses physiotherapists and other healthcare workers must work together and bring about a multi disciplinary approach in their management of chronic osteomyelitis like proper antibiotic therapy based on culture report and by avoiding unnecessary use of third line and broad spectrum antibiotics at the early stage of treatment especially at the primary level.

\section{Bibliography}

1. Shanimole etal.A study on exogenous osteomyelitis: 2006 : pgs 80-90

2. Moodie RL. An introduction to the ancient evidences of disease. Illinois: University of Illinois Press, 1923: Plate XV.

3. Smith N. Medical and surgical memoirs. William A. Francis WA. Baltimore, 1831:97. 
4. Daniel.P. Lew M.D and Francis .A. Waldvogel M.D Osteomyelitis. Current concepts. New Engl.J.Med 1997:337 (6);428

5. Holcombe SJ, Schneider RK, Bramlage LR, et al. Use of antibiotic-impregnated polymethyl methacrylate in horses with openor infected fractures or joints: 19 cases (1987-1995). J Am VetMed Assoc. 1997;211:889-893.

6. Haider ALF, Thamer AH, Sundus SB. Clinical and microbiological evaluation of osteomyelitis. Bahrain Medical Bulletin 2001; 23(2): 61-65.

7. David M. Livermore etal .Detection of $\beta$ lactamase-mediated resistance 2005 august chapter 16:1-16

8. CLSI guidelines M100-S 24 ;2014: pgs $110-112$. 